\title{
BMJ Global Health Global burden of post-traumatic stress disorder and major depression in countries affected by war between 1989 and 2019: a systematic review and meta- analysis
}

Thole H Hoppen (D) , ${ }^{1}$ Stefan Priebe, ${ }^{2}$ Inja Vetter, ${ }^{1}$ Nexhmedin Morina ${ }^{1}$

To cite: Hoppen TH, Priebe S, Vetter I, et al. Global burden of post-traumatic stress disorder and major depression in countries affected by war between 1989 and 2019: a systematic review and metaanalysis. BMJ Global Health 2021;6:e006303. doi:10.1136/ bmjgh-2021-006303

Handling editor Seye Abimbola

- Additional supplemental material is published online only. To view, please visit the journal online (http://dx.doi.org/10. 1136/bmjgh-2021-006303)

Received 13 May 2021 Accepted 20 July 2021

Check for updates

(c) Author(s) (or their employer(s)) 2021. Re-use permitted under CC BY-NC. No commercial re-use. See rights and permissions. Published by BMJ.

${ }^{1}$ Institute of Psychology, University of Münster, Münster, Germany

${ }^{2}$ Unit for Social and Community Psychiatry, Queen Mary University of London, London, UK

Correspondence to Dr Thole H Hoppen; thoppen@uni-muenster.de

\section{ABSTRACT}

Objective Extensive research has demonstrated high prevalences of post-traumatic stress disorder (PTSD) and major depression (MD) in war-surviving populations. However, absolute estimates are lacking, which may additionally inform policy making, research and healthcare. We aimed at estimating the absolute global prevalence and disease burden of adult survivors of recent wars (1989-2019) affected by PTSD and/or MD. Methods We conducted a systematic literature search and meta-analysis of interview-based epidemiological surveys assessing the prevalence of PTSD and/or MD in representative samples from countries with a recent war history (1989-2019). Drawing on the war definition and geo-referenced data of the Uppsala Conflict Database Programme and population estimates of the United Nations for 2019, we extrapolated the meta-analytic results to absolute global numbers of affected people. Drawing on disability-adjusted life years (DALYS) data of the Global Burden of Diseases Study 2019, we further calculated the PTSD-associated and MD-associated DALYS.

Results Twenty-two surveys ( $\mathrm{N}=15420$ ) for PTSD, 13 surveys for $M D(N=9836)$ and six surveys on the comorbidity of PTSD and MD ( $N=1131)$ were included. Random effects meta-analyses yielded point prevalences of $26.51 \%$ for PTSD and $23.31 \%$ for MD. Of those affected by PTSD, $55.26 \%$ presented with comorbid MD. Prevalence rates were not significantly associated with war intensity and length, time since war, response rate or survey quality. The extrapolation yielded 316 million adult war-survivors globally who suffered from PTSD and/or MD in 2019. War-survivors were almost exclusively living in low/middle-income countries (LMICS) and carried a burden of 3105387 and 4083950 DALYs associated with PTSD and MD, respectively.

Conclusions Since LMICs lack sufficient funding and qualified professionals to provide evidence-based psychological treatments for such large numbers of affected people, alternative and scalable strategies using existing resources in primary care and communities are required. Research is required to assist upscaling.

\section{Key questions}

What is already known?

- Several meta-analyses of epidemiological surveys have demonstrated high prevalences of post-traumatic stress disorder (PTSD) and major depression (MD) in warsurviving populations.

- However, absolute global estimates of prevalence and disease burden are lacking.

- Estimates in absolute numbers may inform policy making, research and healthcare beyond percentages.

\section{What are the new findings?}

- In this systematic review and meta-analysis that included 41 surveys, random effects meta-analyses yielded a point prevalence of $26.51 \%$ for PTSD and $23.31 \%$ for MD.

- Of those affected by PTSD, 55.26\% presented with comorbid MD.

- The extrapolation yielded about 316 million adult war survivors who experienced PTSD and/or MD in 2019 residing in 43 war-ridden countries with a war history between 1989 and 2019 (almost exclusively low/ middle-income countries (LMICS)).

- PTSD and MD were associated with about 3 million and 4 million disability-adjusted life years, respectively.

What do the new findings imply?

- The number of war survivors experiencing PTSD and/or MD creates a massive mental health burden, which is primarily borne by LMICS.

- Tailored approaches for LMICs contexts are necessary to address the presented vast mental health burden.

- Low-cost and scalable solutions that build on available resources are recommended as well as multidisciplinary research to guide evidence-based upscaling.

- The findings generally illustrate the importance of peace-building and maintenance.

\section{INTRODUCTION}

Meta-analyses demonstrate high prevalence rates of post-traumatic stress disorder (PTSD) and major depression (MD) in 
war-affected populations with pooled estimates ranging from $15.3 \%$ to $30.6 \%$ for PTSD and $10.8 \%$ to $30.8 \%$ for MD. ${ }^{1-4}$ However, there is a lack of prevalence estimates and disease burden estimates in absolute numbers. Such absolute estimates are important for three major reasons. First, war affects large populations globally: between 1989 and 2019, about one-sixth of the global population have experienced war within their country of residence. ${ }^{5}{ }^{6}$ Second, absolute numbers add clarity to the scope of war-related mental health burdens and, as such, inform policy making, healthcare and research beyond relative estimates. Third, countries with a recent history of war are almost exclusively low/middle-income countries (LMICs) with limited healthcare resources. ${ }^{7}$ Absolute estimates may reveal particular challenges for mental healthcare in LMICs settings and inform tailored approaches. All previous meta-analyses partly or exclusively involved specific populations precluding extrapolations to general war-surviving populations.

Against this background, we aimed to estimate the absolute global number of war survivors with PTSD and/ or MD, as well as the absolute associated disease burden. For this, we conducted a systematic literature search and meta-analysis on high-quality epidemiological surveys conducted in countries with a history of war within their own territory between 1989 and 2019, and extrapolated results to absolute numbers and the associated disabilityadjusted life years (DALYs) as a measure of disease burden.

\section{METHODS}

\section{Definition of war and war-afflicted country}

We used the definition of war and geo-referenced war-data from the Uppsala Conflict Data Programme (UCDP) from the Department of Peace and Conflict Research of the Uppsala University. ${ }^{5}$ The UCDP supplies geo-referenced war data from 1989 to 2019. Based on the geo-referenced data, we classified war in four countries (ie, India, Israel, Russia and Ukraine) as regional rather than nationally distributed (see https://ucdp.uu.se/) which was relevant for the accuracy of extrapolations, which are described in more detail elsewhere. ${ }^{6}$

\section{Systematic literature search}

Up until September 2017, we relied on our previous systematic literature search with identical search strategy, ${ }^{2}$ which we pre-registered in the PROSPERO database (ID: CRD42016032720; https://www.crd.york.ac.uk/prospero/display_record.php?RecordID=32720). However, for the present report, we excluded surveys that were not representative of general populations. A new systematic literature search was conducted in Medline, PsycINFO and PTSDpubs between 1 August 2017 up until 15 January 2021 (see detailed search strategy in online supplemental eList 1). We conducted the systematic review according to the Preferred Reporting Items for Systematic Reviews and Meta-Analyses (PRISMA) guidelines. ${ }^{8}$ Two authors
(THH, IV) independently conducted all search steps (eg, duplicate detection, title and abstract screen, fulltext screen) as well as all following steps (eg, data extraction, risk of bias assessment); regular meetings between three authors (THH, IV and NM) were held to discuss disagreements. Inclusion and exclusion criteria were set to maximise representativeness of general war surviving populations and, therefore, to allow for extrapolations. Epidemiological surveys were eligible if they met all of the following inclusion criteria: (1) conducted after the first year of war in a country with a history of war between 1989 and 2019 as defined by the UCDP; (2) using a random sampling technique to draw a representative sample from the general population; (3) including at least 50 participants; (4) at least $80 \%$ of the participants were aged 18 years or older and (5) PTSD and/ or MD were measured with a (semi-) structured interview based on the diagnostic criteria reported in any version of the Diagnostic and Statistical Manual for Mental Disorders (DSM) or the International Statistical Classification of Diseases (ICD). There were no restrictions in terms of language or population (other than the mentioned inclusion criteria). In line with the inclusion criterion 2, surveys were excluded if they were conducted in an area with particularly high or low war intensity as compared with the rest of the country, indicated by geo-referenced UCDP data, or if surveys involved help-seeking populations. We also reviewed relevant secondary literature (see PRISMA flow chart; figure 1) ${ }^{14610}$ as well as reference lists of eligible articles. Since all relevant data were reported in the eligible surveys, no contact with authors of primary literature was necessary.

\section{Coding of survey information}

The main outcome was the point prevalence of PTSD, $\mathrm{MD}$ and their comorbidity. We further extracted relevant data for the planned moderator analyses (see later).

\section{Quality assessment}

We assessed the quality of included surveys with a scale that we had developed previously. ${ }^{2}$ The scale is based on the recommendations reported in the Strengthening the Reporting of Observational Studies in Epidemiology guidelines and related meta-analyses, ${ }^{11-13}$ and consists of six quality items (see online supplemental eTable 1). Two authors (THH, IV) independently rated the quality of included trials on the applicable items with $73 \%$ agreement. All disagreements were solved through discussions between three authors (THH, IV and NM). A quality sum score of percentage of the possible sum score was created for each survey since they differed on the number of applicable quality items.

\section{Meta-analysis}

We conducted random effects meta-analyses on FreemanTukey double arcsine transformed prevalence proportions using the inverse variance method. ${ }^{14}$ We used the packages meta (V.4.16-2) ${ }^{15}$ and metafor $(\mathrm{V} .2 .4-0)^{16}$ in $\mathrm{R}$ 


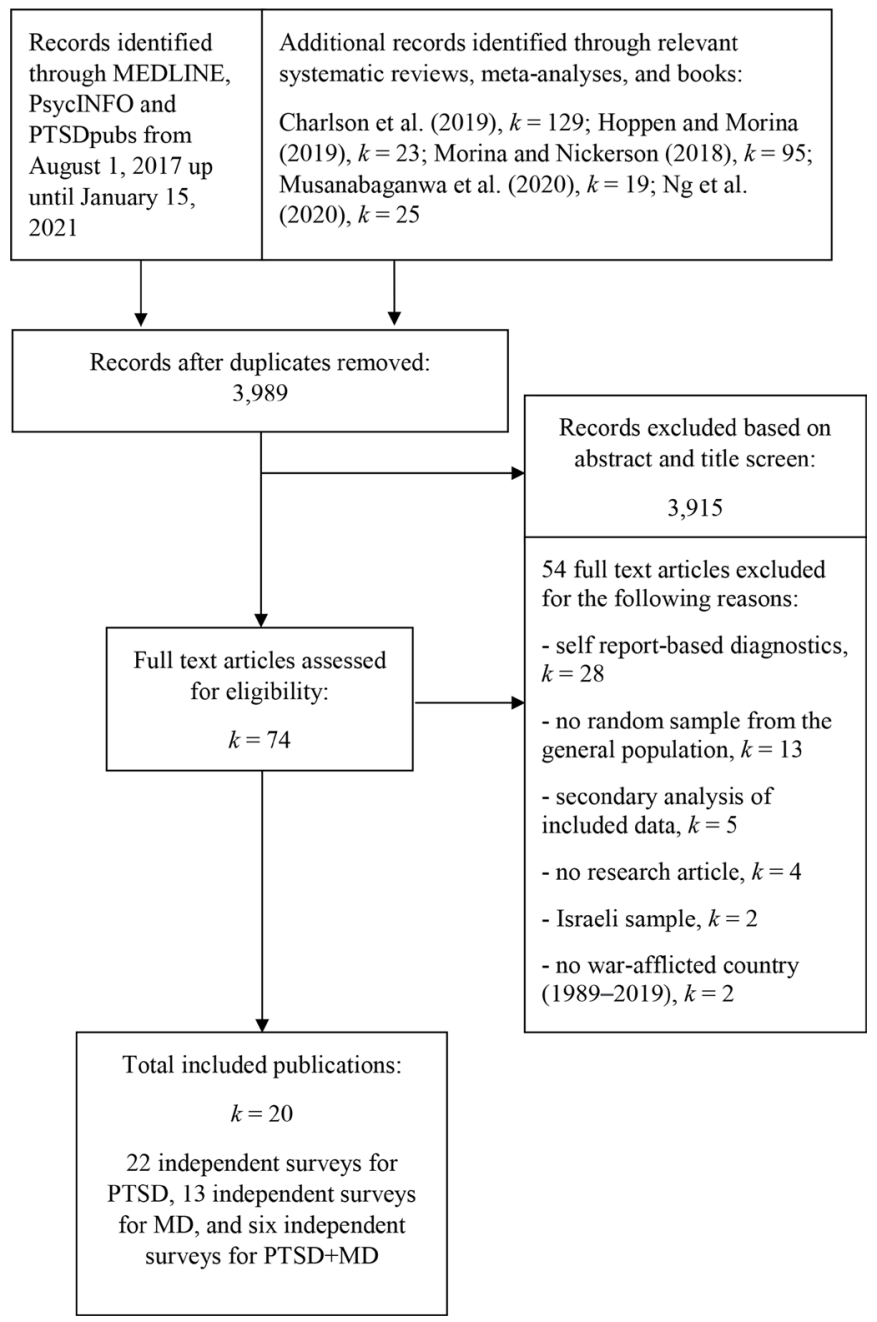

Figure 1 Preferred Reporting Items for Systematic Reviews and Meta-Analyses flowchart of study selection. MD, major depression; PTSD, post-traumatic stress disorder.

(V.3.6.1). ${ }^{17}$ To calculate $95 \%$ CIs for individual studies in the forest plots, we used the Agresti-Coull interval. ${ }^{18}$ Q-statistics and the I2-statistics were calculated to get an estimate of homogeneity in effect sizes. The latter indicates the degree of heterogeneity in percentages. We estimated the between-study variance by calculating $\tau^{2}$-statistics via the restricted maximum likelihood method. ${ }^{19}$ To analyse the potential effects of outliers, we defined outliers as prevalence proportions that were at least 3.3 SD above or below the pooled prevalence proportion and aimed to supply outlier-adjusted results. ${ }^{20}$ To analyse potential publication bias, we visually inspected funnel plots and performed Egger's test of asymmetry. ${ }^{21}$ As recommended, ${ }^{22}$ we did this only in the presence of at least 10 independent estimates. In case of detected asymmetry, we used the trim and fill method, which supplies asymmetry-adjusted results by introducing additional hypothetical studies. ${ }^{23}$ To statistically control for effects of potentially moderating variables (ie, total war deaths, war deaths per 100.000 population, total conflict-related deaths, conflict-related deaths per 100.000, war lengths in years, years since end of war and conduct of survey, response rate, quality of survey, mean age, $\%$ females, $\%$ in a relationship, $\%$ in employment and continent) on prevalence proportions, we planned to perform univariate mixed-method meta-regressions if enough independent surveys reported on the given information (ie, $\mathrm{k} \geq 10) .{ }^{19}$ Data on country-specific war intensity, conflict intensity and war length (accumulative for 1989-2019) was retrieved from the UCDP (https://ucdp.uu.se/). Since there was more than one survey for some countries which experienced multiple wars (Rwanda, Kosovo, Democratic Republic of the Congo, and Palestine for PTSD; Rwanda and Kosovo for MD), we merged cases and non-cases per country for these specific moderator analyses. Some planned moderator analyses (intervention utilisation, non-war-related trauma history) were precluded since these variables were either not assessed or assessed too heterogeneously (differences in defining and assessing mean number of traumatic events per trauma type, breadth of assessed trauma history) to allow for the planned moderator analyses.

\section{Population estimates, extrapolation and income groups}

For all nationally distributed wars, we relied on population estimates of the Population Division of the Department of Economic and Social Affairs (DESA) of the United Nations. ${ }^{24}$ Since people who were very young during war might not be able to remember exposure to war-related events, ${ }^{25}$ we only extrapolated data on adults who were at least 6 years old at the time of the war. Countries where only specific regions were affected by war were: India (Punjab, Nagaland, Kashmir, Assam and Manipur), Ukraine (Donetsk People's Republik, Kharkiv Oblast, Luhansk People's Republic, Zaporizhzhia Oblast and Dnipropetrovsk Oblast), Israel (Gaza strip and West Bank) and Russia (Chechnya). For regional wars, we relied on national consensus data and World Bank population data since DESA does not supply age-grouped regional population estimates. Definitions of LMICs were based on the World Bank classifications (ie, gross national income per capita of less than US\$12 536). ${ }^{26}$

\section{Disease burden estimate}

To estimate the associated disease burden of the global number of war survivors with PTSD and MD, we replied on country-specific DALYs estimates published in the last iteration of the Global Burden of Diseases (GBD) study; the GBD 2019. ${ }^{27}$ Since the GBD 2019 does not report on PTSD data separately, the estimate for all anxiety disorders was used. Total country DALYs for PTSD and all anxiety disorders were retrieved, divided by the total country population and subsequently multiplied by the retrieved number of adult war survivors.

\section{RESULTS}

\section{Article synthesis}

The PRISMA flowchart in figure 1 shows an overview of the survey synthesis. Of the initial 3989 records identified, 74 full texts remained after the title and abstract 
screen for eligibility. After thorough screening of the 74 full texts, a total of 20 eligible publications were included in the present meta-analysis reporting on 22 independent surveys $(\mathrm{N}=15420)$ for PTSD from 12 countries and 3 continents, 13 independent surveys $(\mathrm{N}=9836)$ for $\mathrm{MD}$ from 9 countries and 3 continents, and 6 independent surveys $(\mathrm{N}=1131)$ for PTSD and comorbid MD from 6 countries and 2 continents.

\section{Characteristics of included studies}

An overview of the characteristics of included surveys is provided in table 1 . On average, surveys assessed PTSD and/or MD 6.88 years (weighted mean; $\mathrm{SD}=5.88$ ) after the end of warfare. War intensity and lengths varied considerably across countries. Survey response rates were high with a weighted mean of $88.91 \%(\mathrm{SD}=11.10)$. Most surveys used mental health professionals as interviewers who were trained for the purpose of the survey. The most frequently used interview measure was the Mini International Neuropsychiatric Interview ${ }^{28}$ for both PTSD and MD. Quality of surveys was moderate overall with a weighted mean of $34.92 \%$ ( $\mathrm{SD}=10.94$ ) of the maximum attainable quality sum scores. None of the included surveys involved a formal psychometric validation of translated measures.

\section{Meta-analytic results}

Prevalence of PTSD and MD

Figure 2 shows forest plots of prevalence of PTSD and $\mathrm{MD}$ in the included surveys. Random effects models yielded a pooled point prevalence of $26.51 \% \quad(\mathrm{k}=22$, 95\% CI 22.17 to 31.10$)$ for PTSD. Heterogeneity was large $\left(I^{2}=98 \%, Q=1057.13, \quad \mathrm{p}<0.001\right)$. No statistical outliers were observed. The funnel plot (see online supplemental eFigure 1) and Egger's test of asymmetry $(\mathrm{t}=0.77, \mathrm{p}=0.453)$ did not indicate publication bias. For $\mathrm{MD}$, the random effects model yielded a pooled point prevalence of $23.31 \%$ ( $\mathrm{k}=13,95 \%$ CI 18.55 to 28.42 ) with large heterogeneity $\left(\mathrm{I}^{2}=96.1 \%, \mathrm{Q}=310.72, \mathrm{p}<0.001\right)$. No statistical outliers were observed. Again, the funnel plot (see online supplemental eFigure 2) and Egger's test of asymmetry $(\mathrm{t}=0.77, \mathrm{p}=0.457)$ did not indicate publication bias. For the comorbidity between PTSD and $\mathrm{MD}$, the random effects model yielded a pooled point prevalence of $55.26 \%$ ( $\mathrm{k}=6,95 \%$ CI 42.11 to 68.05 ) with large heterogeneity $\left(I^{2}=95.6 \%, Q=113.39, p<0.001\right.$; see the corresponding forest plot in online supplemental eFigure 3). No statistical outliers were observed. We used pooled point prevalence in the extrapolation to absolute numbers.

\section{Moderator results}

In the meta-regressions on prevalence of PTSD and MD, none of the analysed potential moderators was found to be significantly related (see online supplemental eTable 2). Meta-regressions for comorbidity point prevalence were precluded $(\mathrm{k}<10)$.

\section{Extrapolation to absolute numbers and DALYs}

Table 2 shows point prevalence estimates for PTSD, MD and their comorbidity per country as well as globally. We estimate that a total of 854653860 adult war survivors were alive in 2019 and resided in one of 43 countries which experienced at least one war between 1989 and 2019. Of these, 849754461 were residing in LMICs. Based on the meta-analytic summary of epidemiological surveys, the extrapolation yielded that, in 2019, about 227 million adult war survivors globally experienced PTSD (95\% CI 189476761 to 265797 350) and about 199 million experienced MD (95\% CI 158538291 to 242 892 627). Based on the meta-analytic results on comorbidity point prevalence, about 110 million $(95 \%$ CI 83 891464 to 135569084 ) adult war survivors globally experienced comorbid PTSD and MD. Consequently, about 315699683 adult war survivors globally experienced PTSD and/or MD in 2019 in 43 war-afflicted countries. Of these, 313889900 were residing in LMICs. Only two countries affected by war (Kuwait and Croatia) were considered high-income. Extrapolations to disease burden are also provided in table 2. When the GBD 2019 results are taken as a reference, the extrapolations yielded 3127089 PTSD-associated DALYs and 4114663 MD-associated DALYs across 43 war-affected countries, of which 3105387 (PTSD) and 4083950 (MD) were located in LMICs.

\section{DISCUSSION \\ Main findings}

We aimed to estimate the absolute global number of war survivors with PTSD and/or MD and the associated disease burden in countries that experienced warfare within their own territory between 1989 and 2019. Extrapolation informed by meta-analysis yielded about 316 million adult survivors of war experiencing PTSD and/or MD globally. Almost all war survivors of recent wars reside in LMICs carrying a global accumulated burden of 3 million PTSD-associated DALYs and 4 million MD-associated DALYs.

\section{Strengths and limitation}

We estimated the absolute global number of war survivors with PTSD and/or MD by conducting an up-to-date and comprehensive systematic literature search. We maximised validity of extrapolations by only including interviewbased epidemiological data from random general population samples. The extrapolations to absolute numbers may enable professionals from various disciplines to better grasp the burden of PTSD and MD on survivors of war and guide decision making to ultimately improve mental health of survivors.

Our study also has several limitations. The metaanalyses relied on only 41 surveys. This primarily reflects the current state of literature on war survivors that has mostly focused on refugees or other special war-surviving populations rather than general populations. ${ }^{29}$ In fact, 


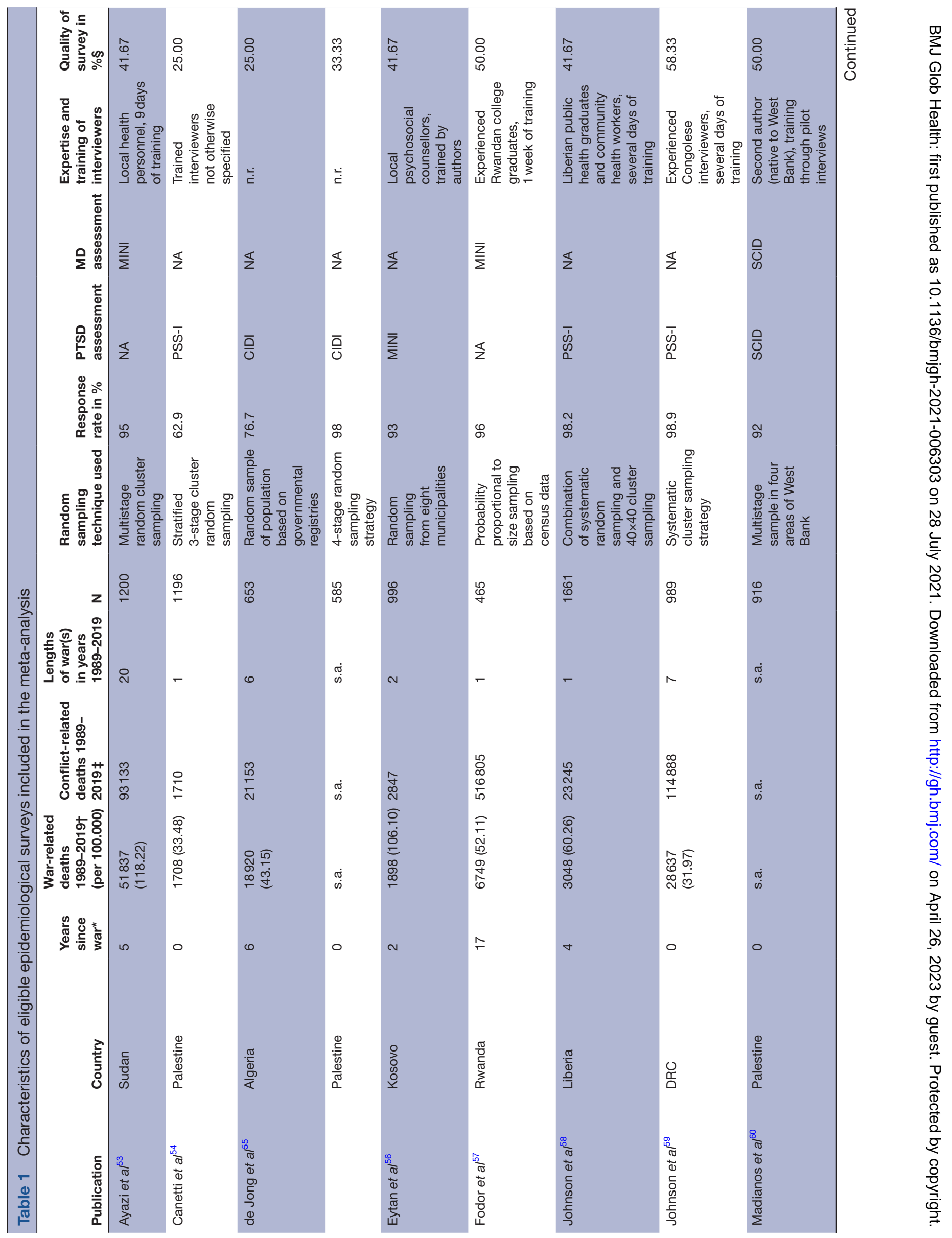




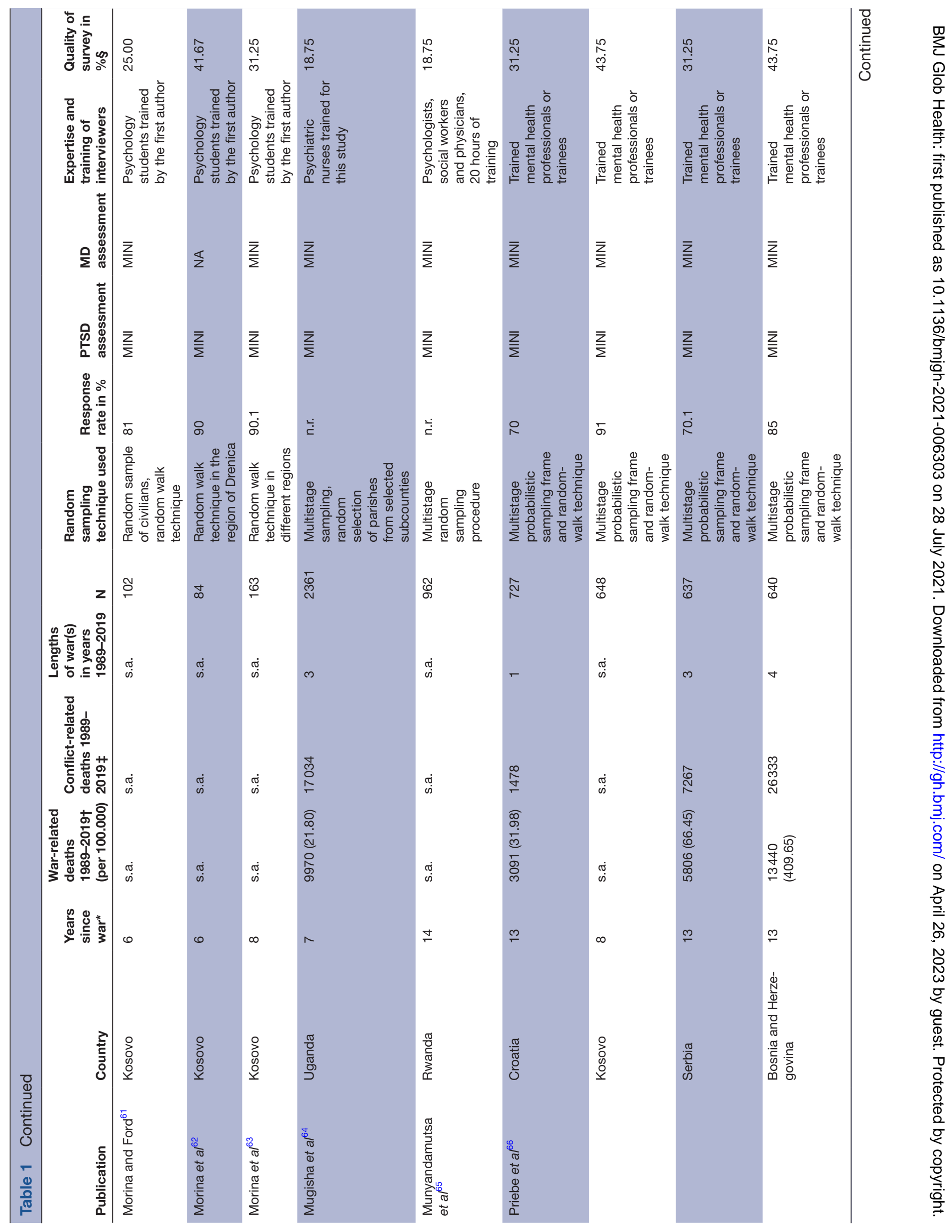



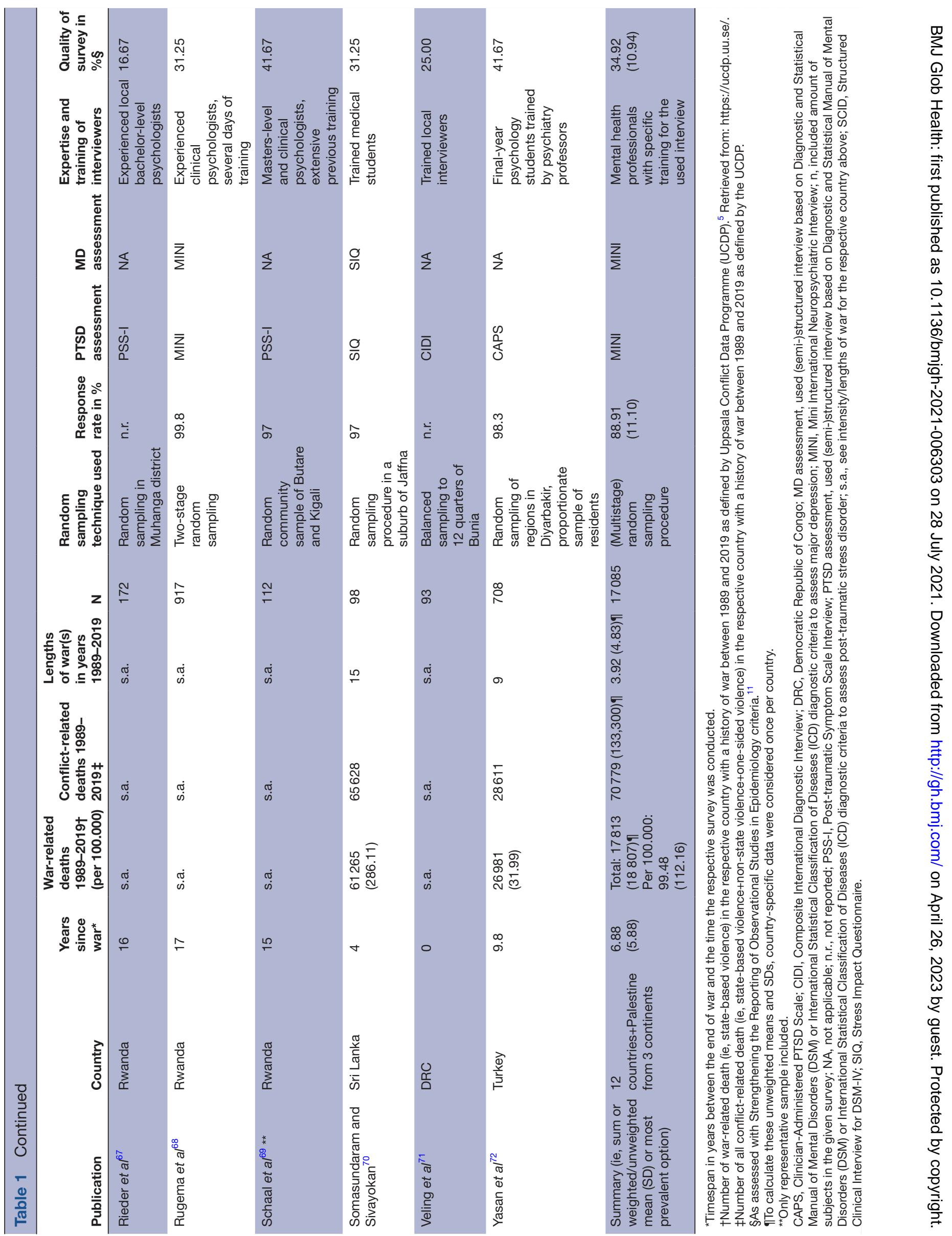
Study

Canetti et al., 2010

De Jong \& al., 2001 (Algeria)

De Jong \& al., 2001 (Gaza)

Eytan et al., 2004

Johnson et al., 2008

Johnson et al., 2010

Madianos et al. 2011

Morina \& Ford, 2008

Morina et al. 2008

Morina et al., 2010

Mugisha et al., 2015

Munyandamutsa et al , 2012

Priebe et al., 2010 (Croatia)

Priebe et al., 2010 (Kosovo)

Priebe et al., 2010 (Serbia)

Priebe et al., 2010 (Bosnia)

Rieder \& Elbert, 2013

Rugema et al., 2015

Schaal et al., 2012

Somasundaram \& Sivayokan, 1994

Veling et al., 2013

Yasan et al., 2009

Fixed effect model

Random effects model

Heterogeneity: $I^{2}=98 \%, \tau^{2}=0.0137, p<0.01$

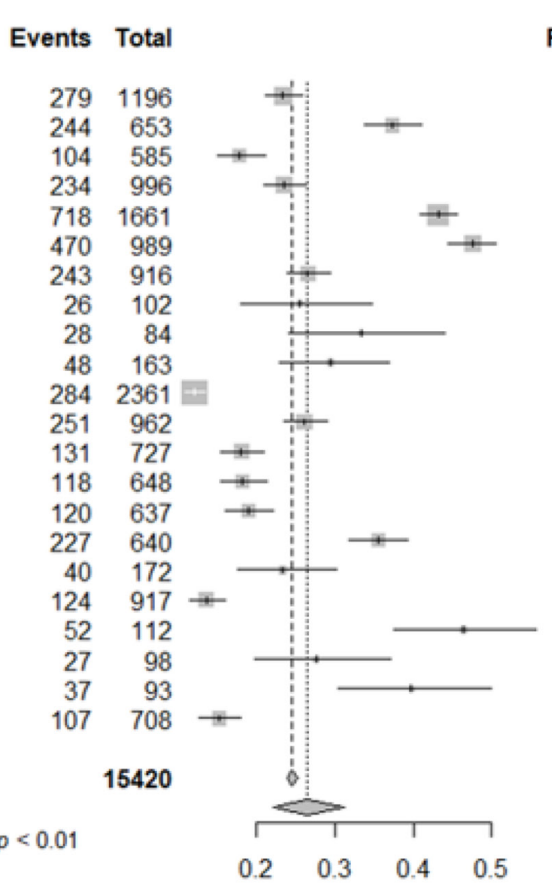

Weight Weight

Proportion $\quad 95 \%-\mathrm{Cl}$ (fixed) (random)

$0.23[0.21 ; 0.26] \quad 7.8 \% \quad 4.8 \%$

$0.37[0.34 ; 0.41] \quad 4.2 \% \quad 4.7 \%$

$0.18[0.15 ; 0.21] \quad 3.8 \%-4.7 \%$

$0.23[0.21 ; 0.26] \quad 6.5 \% \quad 4.7 \%$

$0.43[0.41 ; 0.46] \quad 10.8 \% \quad 4.8 \%$

$0.48[0.44 ; 0.51] \quad 6.4 \%-4.7 \%$

$0.27[0.24 ; 0.29] \quad 5.9 \% \quad 4.7 \%$

$0.25[0.18 ; 0.35] \quad 0.7 \% \quad 4.1 \%$

$0.33[0.24 ; 0.44] \quad 0.5 \% \quad 4.0 \%$

$0.29[0.23 ; 0.37] \quad 1.1 \% \quad 4.3 \%$

$0.12[0.11 ; 0.13] \quad 15.3 \% \quad 4.8 \%$

$0.26[0.23 ; 0.29] \quad 6.2 \% \quad 4.7 \%$

$0.18[0.15 ; 0.21] \quad 4.7 \% \quad 4.7 \%$

$0.18[0.15 ; 0.21] \quad 4.2 \%-4.7 \%$

$0.19[0.16 ; 0.22] \quad 4.1 \% \quad 4.7 \%$

$0.35[0.32 ; 0.39] \quad 4.2 \% \quad 4.7 \%$

$0.23 \quad[0.18 ; 0.30] \quad 1.1 \% \quad 4.4 \%$

$0.14[0.11 ; 0.16] \quad 5.9 \% \quad 4.7 \%$

$0.46[0.37 ; 0.56] \quad 0.7 \% \quad 4.2 \%$

$0.28[0.20 ; 0.37] \quad 0.6 \% \quad 4.1 \%$

$0.40[0.30 ; 0.50] \quad 0.6 \% \quad 4.0 \%$

$0.15[0.13 ; 0.18] \quad 4.6 \% \quad 4.7 \%$

$0.25[0.24 ; 0.25] 100.0 \%$ $0.27[0.22 ; 0.31] \quad-\quad 100.0 \%$

\begin{tabular}{|c|c|c|c|c|c|c|c|c|}
\hline Study & Events & Total & & & Proportion & $95 \%-\mathrm{Cl}$ & $\begin{array}{r}\text { Weight } \\
\text { (fixed) }\end{array}$ & $\begin{array}{l}\text { Weight } \\
\text { (random) }\end{array}$ \\
\hline Ayazi et al., 2012 & 189 & 1200 & \multirow[t]{2}{*}{$\mp$} & & 0.16 & {$[0.14 ; 0.18]$} & $12.2 \%$ & $8.0 \%$ \\
\hline Fodor et al. 2015 & 134 & 465 & & $\longrightarrow$ & 0.29 & {$[0.25 ; 0.33]$} & $4.7 \%$ & $7.8 \%$ \\
\hline Madianos et al. 2011 & 97 & $916 \mp$ & & & 0.11 & {$[0.09 ; 0.13]$} & $9.3 \%$ & $8.0 \%$ \\
\hline Morina \& Ford, 2008 & 32 & 102 & & & 0.31 & {$[0.23 ; 0.41]$} & $1.0 \%$ & $6.7 \%$ \\
\hline Morina, Ford et al., 2010 & 64 & 163 & & \multirow[b]{2}{*}{+} & 0.39 & {$[0.32 ; 0.47]$} & $1.7 \%$ & $7.2 \%$ \\
\hline Mugisha et al., 2015 & 582 & 2361 & & & 0.25 & {$[0.23 ; 0.26]$} & $24.0 \%$ & $8.1 \%$ \\
\hline Munyandamutsa et al., 2012 & 218 & 962 & 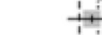 & & 0.23 & {$[0.20 ; 0.25]$} & $9.8 \%$ & $8.0 \%$ \\
\hline Priebe et al., 2010 (Croatia) & 154 & 727 & +1 & & 0.21 & {$[0.18 ; 0.24]$} & $7.4 \%$ & $7.9 \%$ \\
\hline Priebe et al., 2010 (Kosovo) & 242 & 648 & & & 0.37 & {$[0.34 ; 0.41]$} & $6.6 \%$ & $7.9 \%$ \\
\hline Priebe et al., 2010 (Serbia) & 167 & 637 & & $\mp$ & 0.26 & {$[0.23 ; 0.30]$} & $6.5 \%$ & $7.9 \%$ \\
\hline Priebe et al., 2010 (Bosnia) & 70 & $640 \div$ & & $=$ & 0.11 & {$[0.09 ; 0.14]$} & $6.5 \%$ & $7.9 \%$ \\
\hline Rugema et al., 2015 & 179 & 917 & +1 & & 0.20 & {$[0.17 ; 0.22]$} & $9.3 \%$ & $8.0 \%$ \\
\hline Somasundaram \& Sivayokan, 1994 & 25 & 98 & & & 0.26 & {$[0.18 ; 0.35]$} & $1.0 \%$ & $6.6 \%$ \\
\hline Fixed effect model & & 9836 & & 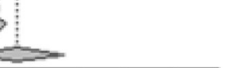 & \multirow{3}{*}{\multicolumn{2}{|c|}{$\begin{array}{l}0.21[0.21 ; 0.22] \\
0.23[0.19 ; 0.28]\end{array}$}} & $100.0 \%$ & \multirow{3}{*}{$100.0 \%$} \\
\hline \multirow{2}{*}{\multicolumn{2}{|c|}{ Heterogeneity. $I^{2}=96 \%, \tau^{2}=0.0108, p<0.01$}} & & $\leq$ & \multirow{2}{*}{\begin{tabular}{cc|c|c|} 
& & 1 & \\
0.25 & 0.30 .35 & 0.40 .45
\end{tabular}} & & & - & \\
\hline & & & 0.15020 & & & & & \\
\hline
\end{tabular}

Figure 2 Forest plots for point prevalence of post-traumatic stress disorder (top) and major depression (bottom).

the current literature base on interview-based randomly sampled surveys covers only 12 countries (and Palestine) and for the remaining 30 war-affected countries such samples are currently lacking. Therefore, our summary of the available literature might not be generalisable to countries with lacking data. On the notion of generalisability to countries with lacking data, it is worthwhile to check whether countries with available data may differ from countries without such data in terms of war-intensity. As can be seen in table 1 , countries with available data bewailed on average 17813 war-related deaths from 1989 to 2019 ( $\mathrm{SD}=18807)$ which translates into 99.48 war-related deaths per 100.000 population $(\mathrm{SD}=112.16)$. Whereas countries with missing data on average bewailed 40042 ( $\mathrm{SD}=71980$ ) or 183.17 per 100.000 population $(\mathrm{SD}=339.65)$. Across all 43 war-afflicted countries, an average of $33322(\mathrm{SD}=61593)$ individuals or 155.97 per
$100.000(\mathrm{SD}=288.95)$ died due to war events. This demonstrates that the war-afflicted countries with available data are somewhat below average in terms of war-intensity. The performed moderator analyses did not yield significant differences in prevalence rates across 12 war-affected countries (plus Palestine) despite varying degrees of warintensity and war-length (see online supplemental eTable 2 ). This finding may be unexpected, since higher intensity of trauma has been shown to relate to higher risk and prevalences of PTSD generally ${ }^{30}$ and also in the context of war trauma ${ }^{31}$ and genocide such as the Holocaust. ${ }^{32}$ Therefore, the results of this moderator analysis should be interpreted with caution as a dose-response relationship between war intensity and prevalences of traumarelated disorders appears plausible. ${ }^{31}$

Also related to the issue of limited data and generalisability, extrapolative accuracy is naturally restrained. Due 


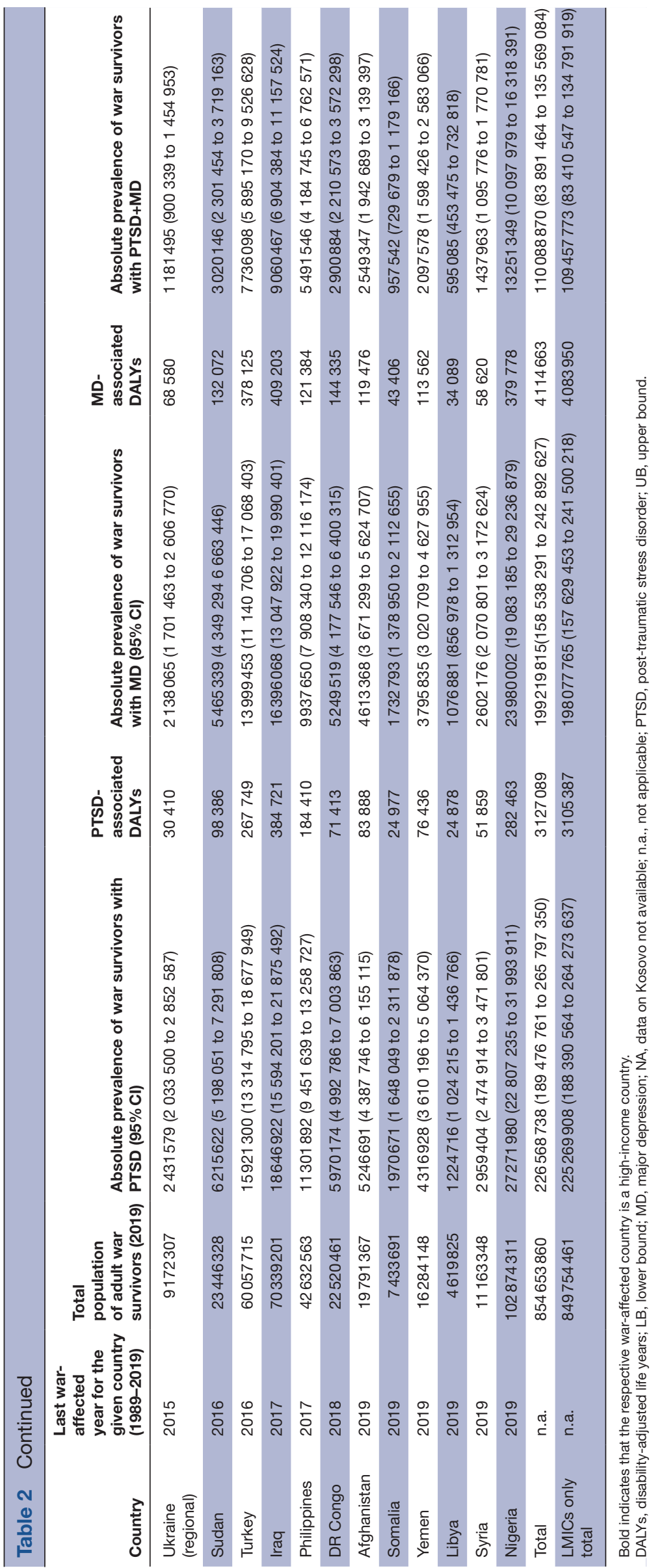


to the general scarcity of data, we had to rely on pooled prevalences of PTSD and MD for extrapolations. In the light of varying degrees of war intensity and lengths as well as more general country-specific differences, such an approach is limited. However, the CIs for the pooled PTSD and MD prevalences were fairly narrow $(22.17 \%$ to $31.10 \%$ and $18.55 \%$ to $28.42 \%$, respectively) indicating fairly similar prevalences of PTSD and MD across the included surveys from 12 war-affected countries (plus Palestine) from three continents. Similarly, the moderator analysis on pooled prevalences by continent did not yield significant differences in PTSD prevalences across the three war-afflicted continents (ie, Africa, Asia and Europe). Surveys on MD were too scarce to allow for this moderator analysis. As more data accumulates, more fine-grained meta-analyses and, consequently, more finegrained extrapolations will become possible.

Another potential limitation is that the current literature base exclusively covers cross-sectional surveys and lacks longitudinal data on remission from PTSD and MD. In their summary of the World Mental Health (WMH) Surveys, Kessler et al reported that remission of warrelated PTSD would steeply increase about 6 years after exposure. The remission rate was reported to rise from about $20 \%$ at 5 years after war to about $70 \%$ at 6 years after war. ${ }^{33}$ In our review, the mean time between war and the assessment of disorders across all included surveys was 6.88 years. In our moderator analyses (see online supplemental eTable 2), the number of years between the end of the (last) war and the conduct of the survey was not found to be related to prevalence rates. This finding is at odds with previous research as illustrated by the above-mentioned summary of the WMH surveys. Yet, several factors might explain why remission rates may be dampened in post-war settings. Besides war-trauma, nonwar-related traumatic experiences and difficult socioeconomic conditions may also influence the development and maintenance of PTSD and MD. ${ }^{34}{ }^{35}$ Socioeconomic risk factors are more prevalent in LMICs with a history of war as compared with the countries included in the WHM surveys which were mostly high-income countries. Furthermore, individuals with mental disorders in LMICs are less likely to receive appropriate healthcare, ${ }^{36-38}$ and PTSD as well as MD, if left untreated, may follow a chronic course. ${ }^{39}{ }^{40}$ However, while remission rates post-conflict might be dampened in war-ridden LMICs for various reasons, a degree of remission is still to be expected particularly over several decades as illustrated by longterm epidemiological data on WWII survivors. ${ }^{41-43}$ Therefore, null findings more probably boil down to a lack of longer-term data rather than lacking remissions per se.

Another potential limitation concerns heterogeneity in outcomes based on different nosology. We included surveys that conducted diagnostic interviews based on any ICD or DSM iteration, which use different criteria for defining PTSD and MD. Finally, this study estimates the disease burden for PTSD. Since the GBD 2019 does not report on PTSD DALYs separately, all anxiety disorder
DALYs had to be used. The presented estimate, therefore, may overestimate or underestimate the PTSD-associated DALYs. The GBD study has already announced that it will report data on PTSD separately in coming iterations, which will allow for more accurate extrapolations.

\section{Comparison with the literature}

The pooled PTSD and MD prevalences are slightly lower than reported prevalences in most meta-analyses on these conditions in war-surviving populations (ie, $\geq 30 \%) .{ }^{3} 429$ In our previous meta-analyses, we found similarly high prevalences (ie, 24\%-26\% for PTSD and 23\%-27\% for MD). ${ }^{26}$ However, recent estimates by the WHO are considerably lower with $15.3 \%$ for PTSD and $10.8 \%$ for MD. ${ }^{1}$ As mentioned before, all previous metaanalyses partly or exclusively involved specific populations (eg, refugees, bereaved individuals) and precluded extrapolations to general war-surviving. Furthermore, related meta-analyses included self-report-based data. ${ }^{1}$ Self-report-based measures of PTSD (eg, PTSD CheckList - Civilian Version) and MD (eg, Patient Health Questionnaire -9) either are not validated for LMICs or have poor psychometric properties in LMICs. ${ }^{44}$ To our knowledge, we performed the first meta-analysis that exclusively included representative interview-based data and, therefore, allowed for more valid extrapolations. We aimed at estimating the absolute prevalence and disease burden of PTSD and MD in war-afflicted countries, irrespective of assumptions about their aetiology. The elevated prevalences of PTSD and MD in war-surviving populations are not to be mistaken as solely caused by war-related trauma. The aetiologies of PTSD and MD are complex and, besides war experiences, non-war-related traumatic experiences, psychological stressors and aversive social conditions can play a role in the development and maintenance of PTSD and MD. However, independently of the precise aetiology of the disorders, the reported prevalences reflect the extent of the total burden and the need for help due to PTSD and MD in war-surviving populations.

\section{Clinical, policy and research implications}

In theory, effective psychological interventions for both youth and adult survivors of mass conflict do exist. ${ }^{38} 45$ However, most LMICs lack the resources in terms of both funding and qualified staff to provide evidence-based psychological treatments for all affected war survivors. ${ }^{36} 3746$ While the allocation of financial and human resources for mental healthcare should surely increase, ${ }^{36} 47$ other approaches than specialised treatments are needed to address the mental health needs of survivors of war. For this, mental healthcare should be as much as possible integrated into the overall response to healthcare following wars. This may include strengthening of primary care to address mental disorders in primary care, task-sharing of psychosocial interventions with trained non-professional individuals, involving families and informal carers, using digital platforms to 
facilitate the delivery of interventions, and the development and implementation of community-based interventions. ${ }^{4-52}$ All these options may benefit from more systematic research to inform public health policies and practice.

\section{CONCLUSIONS}

The effects of exposure to war place a large mental health burden on the affected countries. An extrapolation from relative prevalence of PTSD and MD to absolute numbers suggests that hundreds of millions adult war survivors globally are affected. Countries with a recent history of war are almost exclusively LMICs. These countries lack the resources to provide specialised treatments for most of the affected war survivors. Therefore, alternative strategies-such as low-cost and technology-based interventions that build on existing resources-should be brought forward to meet the high burden of war-related mental disorders. The presented results generally illustrate the importance of peace-building and maintenance.

Twitter Thole H Hoppen @HoppenDr

Contributors THH and NM designed the study. THH and IV conducted the systematic literature search and data extraction. THH conducted the statistical analyses. THH wrote the manuscript. NM, SP and IV commented on and contributed to the manuscript.

Funding The authors have not declared a specific grant for this research from any funding agency in the public, commercial or not-for-profit sectors.

Competing interests None declared.

Patient consent for publication Not required.

Provenance and peer review Not commissioned; externally peer reviewed.

Data availability statement All data analysed in this meta-analysis and in the extrapolations is published and publically available.

Supplemental material This content has been supplied by the author(s). It has not been vetted by BMJ Publishing Group Limited (BMJ) and may not have been peer-reviewed. Any opinions or recommendations discussed are solely those of the author(s) and are not endorsed by BMJ. BMJ disclaims all liability and responsibility arising from any reliance placed on the content. Where the content includes any translated material, BMJ does not warrant the accuracy and reliability of the translations (including but not limited to local regulations, clinical guidelines, terminology, drug names and drug dosages), and is not responsible for any error and/or omissions arising from translation and adaptation or otherwise.

Open access This is an open access article distributed in accordance with the Creative Commons Attribution Non Commercial (CC BY-NC 4.0) license, which permits others to distribute, remix, adapt, build upon this work non-commercially, and license their derivative works on different terms, provided the original work is properly cited, appropriate credit is given, any changes made indicated, and the use is non-commercial. See: http://creativecommons.org/licenses/by-nc/4.0/.

ORCID iD

Thole H Hoppen http://orcid.org/0000-0002-6050-8696

\section{REFERENCES}

1 Charlson F, van Ommeren M, Flaxman A, et al. New WHO prevalence estimates of mental disorders in conflict settings: a systematic review and meta-analysis. Lancet 2019;394:240-8.

2 Morina N, Stam K, Pollet TV, et al. Prevalence of depression and posttraumatic stress disorder in adult civilian survivors of war who stay in war-afflicted regions. A systematic review and meta-analysis of epidemiological studies. J Affect Disord 2018;239:328-38.

3 Steel Z, Chey T, Silove D, et al. Association of torture and other potentially traumatic events with mental health outcomes among populations exposed to mass conflict and displacement: a systematic review and meta-analysis. JAMA 2009;302:537-49.

$4 \mathrm{Ng}$ LC, Stevenson A, Kalapurakkel SS, et al. National and regional prevalence of posttraumatic stress disorder in sub-Saharan Africa: a systematic review and meta-analysis. PLoS Med 2020;17:e1003090.

5 UCDP. Uppsala conflict data program (UCDP) conflict encyclopedia. Uppsala University, 2020.

6 Hoppen TH, Morina N. The prevalence of PTSD and major depression in the global population of adult war survivors: a meta-analytically informed estimate in absolute numbers. Eur $J$ Psychotraumatol 2019;10:1578637.

7 Morina N. Mental health among adult survivors of war in low-and middle-income countries: epidemiology and treatment outcome. In Morina N, Nickerson A, eds. Mental health of refugee and ConflictAffected populations: theory, research and clinical practice. Cham: Springer Nature, 2018: 3-14.

8 Moher D, Liberati A, Tetzlaff J, et al. Preferred reporting items for systematic reviews and meta-analyses: the PRISMA statement. PLoS Med 2009;6:e1000097.

9 Morina N, Nickerson A, eds. Mental health of refugee and conflictaffected populations: theory, research and clinical practice. Cham: Springer Nature, 2018.

10 Musanabaganwa C, Jansen S, Fatumo S, et al. Burden of posttraumatic stress disorder in postgenocide Rwandan population following exposure to 1994 genocide against the Tutsi: a metaanalysis. J Affect Disord 2020;275:7-13.

11 von Elm E, Altman DG, Egger M, et al. The strengthening the reporting of observational studies in epidemiology (STROBE) statement: guidelines for reporting observational studies. Int J Surg 2014:12:1495-9.

12 Sanderson S, Tatt ID, Higgins JPT. Tools for assessing quality and susceptibility to bias in observational studies in epidemiology: a systematic review and annotated bibliography. Int J Epidemiol 2007;36:666-76.

13 Wang W, Fan J, Huang G, et al. Meta-analysis of prevalence of erectile dysfunction in mainland China: evidence based on epidemiological surveys. Sex Med 2017;5:e19-30.

14 Barendregt JJ, Doi SA, Lee YY, et al. Meta-analysis of prevalence. J Epidemiol Community Health 2013;67:974-8.

15 Balduzzi S, Rücker G, Schwarzer G. How to perform a meta-analysis with R: a practical tutorial. Evid Based Ment Health 2019;22:153-60.

16 Viechtbauer W. Conducting meta-analyses in $\mathrm{R}$ with the metafor package. Comput Softw 2010;36:313-20.

17 R Core Team. R: a language and environment for statistical computing. Vienna, Austria, 2015.

18 Agresti A, Coull BA. Approximate is better than "exact" for interval estimation of binomial proportions. Am Stat 1998;52:119-26.

19 Schwarzer G, Carpenter JR, Rücker G. Meta-analysis with R. Springer, 2015

20 Tabaschnick BG, Fidell LS. Using multivariate statistics. 6th edn. Boston: Pearson, 2013.

21 Egger M, Smith GD, Schneider M, et al. Bias in meta-analysis detected by a simple, graphical test. BMJ 1997;315:629-34.

22 Sterne JAC, Sutton AJ, loannidis JPA, et al. Recommendations for examining and interpreting funnel plot asymmetry in meta-analyses of randomised controlled trials. BMJ 2011;343:d4002.

23 Duval S. A nonparametric "trim and fill" method of accounting for publication bias in meta-analysis. J Am Stat Assoc 2000;95:89-98.

24 United Nations. World population prospects 2019: department of economic and social Affairs, 2020. Available: https://population.un. org/wpp/Download/Standard/Population/

25 Morina N, von Lersner U, Prigerson HG. War and bereavement: consequences for mental and physical distress. PLoS One 2011;6:e22140.

26 Fantom N, Serajuddin U. The World Bank's classification of countries by income. The World Bank, 2016.

27 Vos T, Lim SS, Abbafati C, et al. Global burden of 369 diseases and injuries in 204 countries and territories, 1990-2019: a systematic analysis for the global burden of disease study 2019. Lancet 2020;396:1204-22.

28 Sheehan DV, Lecrubier Y, Harnett Sheehan K, et al. The validity of the mini international neuropsychiatric interview (mini) according to the SCID-P and its reliability. Eur Psychiatry 1997;12:232-41.

29 Blackmore R, Boyle JA, Fazel M, et al. The prevalence of mental illness in refugees and asylum seekers: a systematic review and meta-analysis. PLoS Med 2020;17:e1003337.

30 Brewin CR, Andrews B, Valentine JD. Meta-analysis of risk factors for posttraumatic stress disorder in trauma-exposed adults. $J$ Consult Clin Psychol 2000;68:748. 
31 Buydens-Branchey L, Noumair D, Branchey M. Duration and intensity of combat exposure and posttraumatic stress disorder in Vietnam veterans. J Nerv Ment Dis 1990;178:582-7.

32 Kuch K, Cox BJ. Symptoms of PTSD in 124 survivors of the holocaust. Am J Psychiatry 1992;149:337-40.

33 Kessler RC, Aguilar-Gaxiola S, Alonso J, et al. Trauma and PTSD in the who world mental health surveys. Eur $\mathrm{J}$ Psychotraumatol 2017;8:1353383.

34 Benjet C. Childhood adversities of populations living in lowincome countries: prevalence, characteristics, and mental health consequences. Curr Opin Psychiatry 2010;23:356-62.

35 Benjet C, Bromet E, Karam EG, et al. The epidemiology of traumatic event exposure worldwide: results from the world mental health survey Consortium. Psychol Med 2016;46:327-43.

36 Patel V, Saxena S, Lund C, et al. The lancet commission on global mental health and sustainable development. Lancet 2018;392:1553-98.

37 Patel V, Maj M, Flisher AJ, et al. Reducing the treatment gap for mental disorders: a WPA survey. World Psychiatry 2010;9:169-76.

38 Morina N, Malek M, Nickerson A, et al. Psychological interventions for post-traumatic stress disorder and depression in young survivors of mass violence in low- and middle-income countries: metaanalysis. Br J Psychiatry 2017;210:247-54.

39 Morina N, Wicherts JM, Lobbrecht J, et al. Remission from post-traumatic stress disorder in adults: a systematic review and meta-analysis of long term outcome studies. Clin Psychol Rev 2014;34:249-55.

40 Richards D. Prevalence and clinical course of depression: a review. Clin Psychol Rev 2011;31:1117-25.

41 Lis-Turlejska M, Szumiał S, Drapała I. Posttraumatic stress symptoms among Polish World war II survivors: the role of social acknowledgement. Eur J Psychotraumatol 2018;9:1423831.

42 Bramsen I, van der Ploeg HM. Fifty years later: the long-term psychological adjustment of ageing World war II survivors. Acta Psychiatr Scand 1999;100:350-8.

43 Frounfelker R, Gilman SE, Betancourt TS, et al. Civilians in world war II and DSM-IV mental disorders: results from the world mental health survey initiative. Soc Psychiatry Psychiatr Epidemiol 2018;53:207-19.

44 Ali G-C, Ryan G, De Silva MJ. Validated screening tools for common mental disorders in low and middle income countries: a systematic review. PLoS One 2016;11:e0156939.

45 Morina N, Malek M, Nickerson A, et al. Meta-analysis of interventions for posttraumatic stress disorder and depression in adult survivors of mass violence in low- and middle-income countries. Depress Anxiety 2017;34:679-91.

46 Osborn TL, Wasil AR, Weisz JR, et al. Where is the global in global mental health? A call for inclusive multicultural collaboration. Gen Psychiatr 2020;33:e100351.

47 Jakovljevic MB. Resource allocation strategies in southeastern European health policy. Eur J Health Econ 2013;14:153-9.

48 Dawson KS, Rahman A. Low intensity interventions for psychological symptoms following mass trauma. In: Morina N, Nickerson A, eds. Mental health of refugee and Conflict-Affected populations: theory, research and clinical practice. Cham: Springer Nature, 2018: 341-56.

49 Naslund JA, Aschbrenner KA, Araya R, et al. Digital technology for treating and preventing mental disorders in low-income and middle-income countries: a narrative review of the literature. Lancet Psychiatry 2017;4:486-500.

50 Patel V, Simon G, Chowdhary N, et al. Packages of care for depression in low- and middle-income countries. PLoS Med 2009;6:e1000159.

51 Rahman A, Hamdani SU, Awan NR, et al. Effect of a multicomponent behavioral intervention in adults impaired by psychological distress in a conflict-affected area of Pakistan: a randomized clinical trial. JAMA 2016;316:2609-17.

52 Singla DR, Kohrt BA, Murray LK, et al. Psychological treatments for the world: lessons from low- and middle-income countries. Annu Rev Clin Psychol 2017;13:149-81.
53 Ayazi T, Lien L, Eide AH, et al. What are the risk factors for the comorbidity of posttraumatic stress disorder and depression in a war-affected population? A cross-sectional community study in South Sudan. BMC Psychiatry 2012;12:175.

54 Canetti D, Galea S, Hall BJ, et al. Exposure to prolonged sociopolitical conflict and the risk of PTSD and depression among Palestinians. Psychiatry 2010;73:219-31.

55 de Jong JT, Komproe IH, Van Ommeren M, et al. Lifetime events and posttraumatic stress disorder in 4 postconflict settings. JAMA 2001;286:555-62.

56 Eytan A, Guthmiller A, Durieux-Paillard S, et al. Mental and physical health of Kosovar Albanians in their place of origin: a post-war 6-year follow-up study. Soc Psychiatry Psychiatr Epidemiol 2011;46:953-63.

57 Fodor KE, Pozen J, Ntaganira J, et al. The factor structure of posttraumatic stress disorder symptoms among Rwandans exposed to the 1994 genocide: a confirmatory factor analytic study using the PCL-C. J Anxiety Disord 2015;32:8-16.

58 Johnson K, Asher J, Rosborough S, et al. Association of combatant status and sexual violence with health and mental health outcomes in postconflict Liberia. JAMA 2008;300:676-90.

59 Johnson K, Scott J, Rughita B, et al. Association of sexual violence and human rights violations with physical and mental health in territories of the eastern Democratic Republic of the Congo. JAMA 2010;304:553-62.

60 Madianos MG, Sarhan AL, Koukia E. Posttraumatic stress disorders comorbid with major depression in West bank, Palestine: a general population cross sectional study. Eur. J. Psychiat. 2011;25:19-31.

61 Morina N, Ford JD. Complex sequelae of psychological trauma among Kosovar civilian war victims. Int J Soc Psychiatry 2008;54:425-36.

62 Morina N, Stangier U, Risch AK. Experiential avoidance in civilian war survivors with current versus recovered posttraumatic stress disorder: a pilot study. Behav Change 2008;25:15-22.

63 Morina N, Ford JD, Risch AK, et al. Somatic distress among Kosovar civilian war survivors: relationship to trauma exposure and the mediating role of experiential avoidance. Soc Psychiatry Psychiatr Epidemiol 2010;45:1167-77.

64 Mugisha J, Muyinda H, Wandiembe P, et al. Prevalence and factors associated with posttraumatic stress disorder seven years after the conflict in three districts in northern Uganda (the Wayo-Nero study). BMC Psychiatry 2015;15:170.

65 Munyandamutsa N, Mahoro Nkubamugisha P, Gex-Fabry M, et al. Mental and physical health in Rwanda 14 years after the genocide. Soc Psychiatry Psychiatr Epidemiol 2012;47:1753-61.

66 Priebe S, Bogic M, Ajdukovic D. Mental disorders following war in the Balkans: a study in 5 countries. Arch Gen Psychiatry 2010;67:518-28.

67 Rieder H, Elbert T. Rwanda - lasting imprints of a genocide: trauma, mental health and psychosocial conditions in survivors, former prisoners and their children. Confl Health 2013;7:6.

68 Rugema L, Mogren I, Ntaganira J, et al. Traumatic episodes and mental health effects in young men and women in Rwanda, 17 years after the genocide. BMJ Open 2015;5:e006778.

69 Schaal S, Weierstall R, Dusingizemungu J-P, et al. Mental health 15 years after the killings in Rwanda: imprisoned perpetrators of the genocide against the Tutsi versus a community sample of survivors. J Trauma Stress 2012;25:446-53.

70 Somasundaram DJ, Sivayokan S. War trauma in a civilian population. Br J Psychiatry 1994;165:524-7.

71 Veling W, Hall BJ, Joosse P. The association between posttraumatic stress symptoms and functional impairment during ongoing conflict in the Democratic Republic of Congo. J Anxiety Disord 2013;27:225-30.

72 Yasan A, Saka G, Ozkan M, et al. Trauma type, gender, and risk of PTSD in a region within an area of conflict. $J$ Trauma Stress 2009;22:663-6. 